\title{
Evaluation of the Efficacy of Sildenafil Citrate Following Severe Head Trauma in an Experimental Rat Model
}

\author{
Bilal KILICARSLAN ${ }^{1}$, Emel KILICARSLAN² ${ }^{2}$ Ceren KIZMAZOGLU ${ }^{3}$, Hasan Emre AYDIN ${ }^{4}$, Ismail KAYA ${ }^{4}$, \\ Ayca Ersen DANYELI ${ }^{5}$, Hamit Selim KARABEKIR ${ }^{3}$
}

\author{
${ }^{1}$ Bitlis Tatvan State Hospital, Department of Neurosurgery, Bitlis, Turkey \\ ${ }^{2}$ Bitlis Tatvan State Hospital, Department of Pathology, Bitlis, Turkey \\ ${ }^{3}$ Dokuz Eylul University, School of Medicine, Department of Neurosurgery, Izmir, Turkey \\ ${ }^{4}$ Dumlupinar University, Evliya Celebi Training and Research Hospital, Department of Neurosurgery, Kutahya, Turkey \\ ${ }^{5}$ Acibadem Mehmet Ali Aydinlar University, School of Medicine, Department of Pathology, Istanbul, Turkey
}

This study has been presented as an oral presentation at the meeting of the $16^{\text {th }}$ International Congress of the World Federation of Neurosurgical Societies between 20 and 25 August 2017 at Istanbul, Turkey.

Corresponding author: Bilal KILICARSLAN drkilicarslan@gmail.com

\section{ABSTRACT}

AIM: To investigate the acute effects of sildenafil citrate in an experimental model of severe head trauma, and to compare it with the efficacy of mannitol, which is an osmotically active agent frequently used in clinical treatment of traumatic brain injury (TBI).

MATERIAL and METHODS: Twenty-eight Wistar-derived albino strain female rats were randomized into four groups comprising seven rats each. These groups were designated as follows: Group I: sham; Group II: TBI; Group III: TBI + mannitol (20\% $1 \mathrm{gr} /$ $\mathrm{kg}$, intraperitoneal); and Group IV: TBI + sildenafil citrate (10 mg/kg, intraperitoneal). Sections prepared following the tissue processing of samples obtained from the right prefrontal cortex and right hippocampal regions of the brains of sacrificed rats were histopathologically evaluated. Fractionator method via the Stereo Investigator software program (Micro Bright Field) was used to count the neurons. Pyknotic neuron count and pyknotic / total neuron count were compared between the groups.

RESULTS: In the comparison of Group II and IV, pyknotic neuron count (prefrontal; group II: $116.00 \pm 30.50$, group IV: $80.00 \pm 19.47$ ) and pyknotic/ total neuron count (prefrontal; group II: $0,30 \pm 0.08$, group IV: $0.21 \pm 0.02$ ) were significantly lower in Group IV in both regions $(p<0.05)$. Similarly, in the comparison of Group II and III, the values in Group III were lower in both regions $(p<0.05)$.

CONCLUSION: Sildenafil citrate decreases neuronal death in the acute phase and produces similar results with mannitol. Therefore, we believe that sildenafil citrate can be a useful adjunct or alternative agent for the clinical treatment of patients with acute TBI.

KEYWORDS: Sildenafil citrate, Mannitol, Severe head trauma, Rat

ABBREVIATIONS: TBI: Traumatic brain injury, PDE-5: Phosphodiesterase type 5, SAH: Subarachnoid hemorrhage, cGMP: Cyclic guanosine monophosphate, NO: Nitric Oxide, $\mu \mathrm{m}$ : Micrometer

\section{INTRODUCTION}

$\mathrm{H}$ ead trauma, a fatal and disabling pathology requiring long-term treatment and care, is a leading cause of death $(12,21,34,37)$. Consecutive primary and secondary injuries lead to fatal and disabling effects of traumatic brain injury (TBI) (8).
Brain swelling following head trauma is one of the major problems that lead to neurological damage (16). Increased intracranial pressure and decreased cerebral perfusion due to cerebral edema result in tissue hypoxia and its harmful effects on neuronal axis (9). Osmotherapy is commonly used to treat cerebral edema and intracranial hypertension in TBI.
Bilal KILICARSLAN (D) : 0000-0002-4938-5197

Emel KILICARSLAN (D): 0000-0003-0243-2694

Ceren KIZMAZOGLU (1) : 0000-0001-6146-0842
Hasan Emre AYDIN (10) : 0000-0002-8932-1542

Ismail KAYA (C) : $0000-0002-5117-8066$
Ayca Ersen DANYELI

(1) : $0000-0001-8015-9916$
Hamit Selim KARABEKIR

(D) : 0000-0003-1173-4483 
Mannitol, which reduces vasogenic, cytotoxic and interstitial brain edema, is also an antioxidant agent $(15,20,42)$.

Sildenafil citrate, a potent phosphodiesterase type 5 (PDE-5) inhibitor, is used to treat erectile dysfunction and pulmonary hypertension $(4,40)$. In addition, it has been studied for its effect on diseases involving the central nervous system, such as stroke, Alzheimer's disease, subarachnoid hemorrhage (SAH), hypoxic-ischemic damage, and neurodegenerative diseases, because it can cross the blood-brain barrier $(2,24,30,38,41,43)$. These studies have demonstrated that PDE-5 inhibitors, including sildenafil citrate, induce vasodilatation by increasing the level of cyclic guanosine monophosphate (cGMP) in the brain through the glutamate - nitric oxide (NO)- cGMP signaling pathway, thus increasing the cerebral blood flow and accelerating functional recovery by acting on inflammatory cells and neurons at the cellular level. Some experimental studies have shown that cGMP also activates anti-apoptotic mechanisms in the brain $(3,11)$. Another experimental study on rats has shown that sildenafil citrate reduces brain edema and infarct volume following stroke (7).

However, in the literature, no study has yet investigated the neuroprotective activity of sildenafil citrate in acute head trauma. Here, we aimed to investigate the acute effect of sildenafil citrate in head trauma and compare it with the efficacy of mannitol, which is an osmotically active agent frequently used in the clinical treatment of head trauma.

\section{MATERIAL and METHODS}

This study was approved by the Experimental Research Ethics Committee of the Faculty of Medicine, Dokuz Eylul University, Turkey (January 12, 2016; Approval No.: 59/2015).

Twenty-eight Wistar-derived albino strain female rats (age: 6-8 weeks; weight: 300-400 grams), which were not previously used in any other study, were obtained from the Faculty of Medicine, Experimental Animal Research Laboratory, Dokuz Eylul University. The rats were fed with standard rat feed (pellets) and were monitored before and during the experiment at room temperature $\left(20^{\circ} \mathrm{C} \pm 2^{\circ} \mathrm{C}\right)$ under 12-hour light/dark conditions, with free access to water for a week. The rats were then randomized into four groups comprising 7 rats each, designated as follows: Group I, sham (rats anesthetized but not induced to trauma); Group II, TBI (rats induced to trauma, no treatment has given); Group III, TBI + mannitol (rats induced to trauma, \%20 mannitol, $1 \mathrm{gr} / \mathrm{kg}$ intraperitoneal, has given as treatment); and Group IV, TBI + sildenafil citrate (Viagra $^{\circledR}$ - Pfizer, U.S.), (10 mg/kg, intraperitoneal) $(6,27,35)$. For anesthesia, Xylazine $\mathrm{HCl}$ (Rompun ${ }^{\circledR}$-Bayer, Turkey)(5-10 $\mathrm{mg} / \mathrm{kg}$; intraperitoneal); and Ketamine (Ketalar ${ }^{\circledR}$-Eczacibasi, Turkey) (50 mg/kg; intraperitoneal;, were used (33). During the experiment, the "Marmarou's weight drop model" was used to induce severe head trauma in rats $(1,22)$. No rats exhibited head fracture, nasal bleeding or mortality. The rats were sacrificed 4 hours after TBI.

\section{Histopathological Examination}

The tissue samples were fixed using $10 \%$ formaldehyde and were embedded in paraffin blocks following routine tissue processing. Crystal violet-stained sections sized $4 \mu \mathrm{m}$ prepared following the routine tissue processing of samples obtained from the right prefrontal cortex and right hippocampal region were evaluated using the Stereo Investigator Software (Micro Bright Field). This software generates unbiased virtual counting spaces in all the related fields and performs the counting process through the "fractionator" method by automatically stepping on the $x-y$ axes. For each section, the related field was selected at $40 \times$ (low) magnification (Figure 1). The counting process was performed at $400 \times$ (high) magnification in 20 counting frames sized $253 \times 176$ micrometer $(\mu \mathrm{m})$, which were randomly determined by the abovementioned software (Figure 2). Small, dense, irregularly shaped pyknotic nuclei and normal neurons were marked using different markers to obtain the number of pyknotic, normal, and total neurons in both the prefrontal and hippocampal regions of each rat.

\section{Statistical Analysis}

All data were statistically analyzed using the SPSS Statistics v15.0 for Windows. $p<0.05$ was considered statistically significant. Between groups comparisons were made using the non-parametric Mann-Whitney $U$-test.

\section{RESULTS}

The pyknotic neuron count and pyknotic / total neuron count were obtained from the samples obtained from both the right prefrontal cortex and right hippocampal regions of all rats. Based on these data, Group I (sham) was compared with Group II (TBI), Group II (TBI) with Group III (TBI + mannitol), Group II (TBI) with Group IV (TBI + sildenafil citrate) and finally, Group III (TBI + mannitol) with Group IV (TBI + sildenafil citrate). Measurements, counting results, average values and $p$ values for the right prefrontal region and the right hippocampus are summarized in Table I, II.

In the comparison of Group I and II, the pyknotic neuron count and pyknotic / total neuron count was significantly higher in Group II (TBI) in both prefrontal and hippocampal

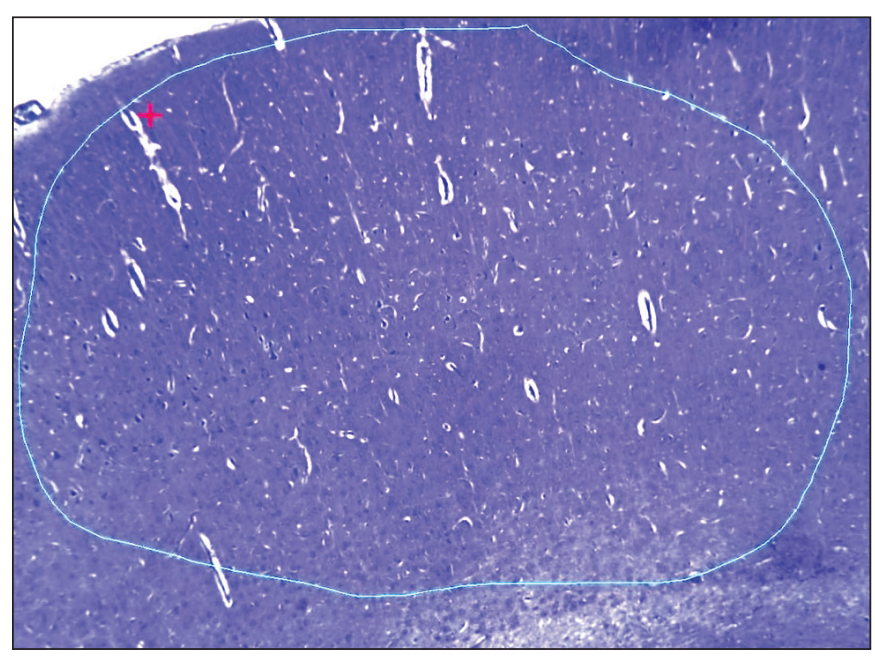

Figure 1: The areas from prefrontal cortex and hippocampus were selected via $40 x$ objective. 
regions $(p<0.05)$. In the comparison of Group II and III, the abovementioned values were significantly lower in Group III (TBI + mannitol) in both regions $(p<0.05)$. Similarly, in the comparison of Group II and IV, the values in Group IV (TBI + sildenafil citrate) were lower in both regions $(p<0.05)$. Finally, in the comparison of Group III and IV, no statistically significant difference was found between the two groups $(p<0.05)$.

\section{DISCUSSION}

Recently, studies reporting positive effects of sildenafil citrate and other PDE-5 inhibitors on the central nervous system have been frequently encountered in literature. For example, certain studies have reported that PDE-5 inhibitors are beneficial following stroke $(7,31,36,44)$. Ozdegirmenci et al. reported that sildenafil has positive effects in preventing

Table I: The Mean Values of Measurements and Counting Results for the Right Prefrontal Cortex in All Groups

\begin{tabular}{lcccc}
\hline & $\begin{array}{c}\text { Group I } \\
(\mathbf{n}=\mathbf{7})\end{array}$ & $\begin{array}{c}\text { Group II } \\
(\mathbf{n}=\mathbf{7})\end{array}$ & $\begin{array}{c}\text { Group III } \\
(\mathbf{n}=\mathbf{7})\end{array}$ & $\begin{array}{c}\text { Group IV } \\
(\mathbf{n}=\mathbf{7})\end{array}$ \\
\hline Pyknotic neuron count & $46.28 \pm 12.90$ & $116.00 \pm 30.50$ & $68.57 \pm 21.96^{\dagger}$ & $80.00 \pm 19.47^{\star}$ \\
\hline Total neuron count & $374.42 \pm 86.42$ & $400.42 \pm 152.81$ & $380.42 \pm 44.89$ & $369.00 \pm 84.01$ \\
\hline Pyknotic / total neuron count & $0.12 \pm 0.02$ & $0,30 \pm 0.08$ & $0.17 \pm 0.05^{\dagger}$ & $0.21 \pm 0.02^{*}$ \\
\hline Total area $\left(\mu \mathrm{m}^{2}\right)$ & $2050522.85 \pm$ & $2480398.57 \pm$ & $2051244.28 \pm$ & $2868950.00 \pm$ \\
& 357292.04 & 445431.24 & 328575.07 & 281475.27 \\
\hline
\end{tabular}

*pyknotic neuron count ( $(=0.025)$, and pyknotic/total neuron count $(p=0.018)$ were significantly lower in group IV than group II. tpyknotic neuron count $(p=0.018)$ and pyknotic/total neuron count $(p=0.006)$ were significantly lower in group III than group II.

Table II: The Mean Values of Measurements and Counting Results for the Right Hippocampus in All Groups

\begin{tabular}{lcccc}
\hline & $\begin{array}{c}\text { Group I } \\
(\mathbf{n}=7)\end{array}$ & $\begin{array}{c}\text { Group II } \\
(\mathbf{n}=7)\end{array}$ & $\begin{array}{c}\text { Group III } \\
(\mathbf{n}=7)\end{array}$ & $\begin{array}{c}\text { Group IV } \\
(\mathbf{n}=\mathbf{7})\end{array}$ \\
\hline Pyknotic neuron count & $32.00 \pm 14.13$ & $71.14 \pm 39.57$ & $24.28 \pm 10.11^{\dagger}$ & $26.42 \pm 6.07^{\star}$ \\
\hline Total neuron count & $349.57 \pm 154.47$ & $264.71 \pm 109.51$ & $231.42 \pm 59.88$ & $269.85 \pm 69.20$ \\
\hline Pyknotic / total neuron count & $0.09 \pm 0.03$ & $0.26 \pm 0.08$ & $0.10 \pm 0.02^{\dagger}$ & $0.10 \pm 0.03^{\star}$ \\
\hline \multirow{2}{*}{ Total area $\left(\mu \mathrm{m}^{2}\right)$} & $1249415.42 \pm$ & $1032509.42 \pm$ & $768854.71 \pm$ & $767153.00 \pm$ \\
& 409275.53 & 270553.04 & 191852.65 & 131385.10 \\
\hline
\end{tabular}

*pyknotic neuron count $(p=0.004)$ and pyknotic/total neuron count $(p=0.002)$ were significantly lower in group IV than group II. tpyknotic neuron count $(p=0.005)$ and pyknotic/total neuron count $(p=0.002)$ were significantly lower in group III than group II.

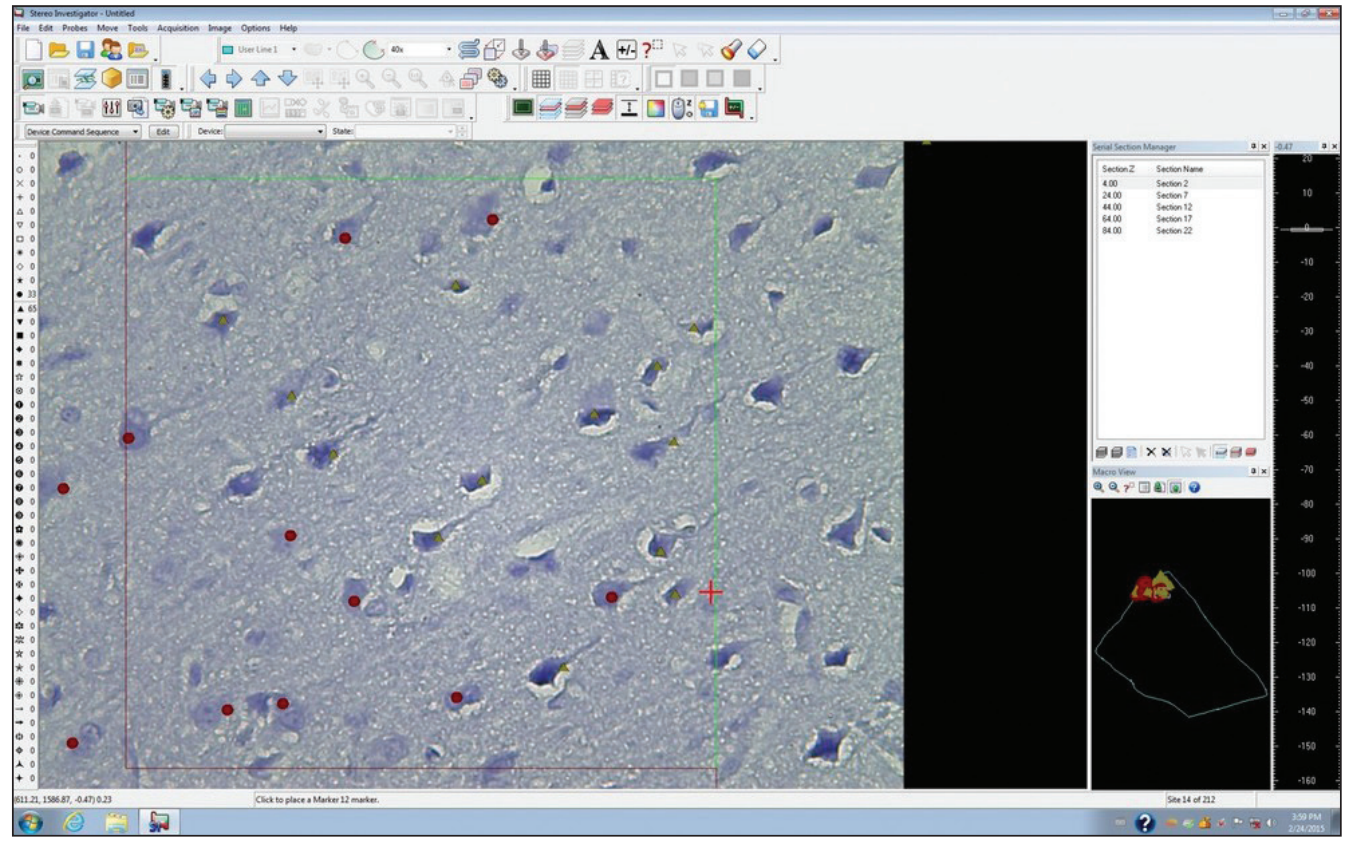

Figure 2: The stereology system allowed us to select and count normal neurons (with red dot), and pyknotic neurons (yellow triangle) in different and automatically randomly selected 20 fields of $400 x$ objective with $253 \times 176 \mu \mathrm{m}$ size. 
ischemia/reperfusion injury in fetal rat brain (24). Another study in neonatal rats reported that sildenafil citrate is very effective in reducing hypoxic-ischemic injury (6). In these studies, these beneficial effects were associated with the fact that sildenafil citrate and some other PDE-5 inhibitors reduce infarct volume by increasing cerebral blood flow and decrease neuron loss by restructuring the extracellular matrix via a number of cellular mechanisms and angiogenesis. Yazdani et al. reported that sildenafil citrate administered at different doses in neonatal hypoxic-ischemic injury in rat pups resulted in increased neuronal counts around the infarct area in the long term (41). Although the just mentioned study did not examine the mechanism of action, it is suggested that sildenafil citrate increases neurogenesis via cellular mechanisms and accelerates brain repair following ischemia. The current study suggests that sildenafil citrate administered following severe head trauma decreases neuronal death in the acute phase.

Molecular events that alter the balance of the post-SAH NOcGMP pathway (26), and lead to vasospasm and ischemia, thus worsening prognosis, are targeted by PDE-5 inhibitors, such as sildenafil citrate, and studies have been conducted in this regard $(10,14,39)$. One such study reported that sildenafil reduces vasospasm and neuronal cell death following SAH but does not alter intracranial pressure (14); other studies reported that both low and high doses of sildenafil lead to vasodilatation in patients with $\mathrm{SAH}$, with no effects on intracranial pressure or no other systemic adverse effects $(10,39)$.

The study conducted by Kara et al., wherein the abovementioned positive effects were also reported following spinal cord injury in rabbits, is remarkable (17). Kara et al. reported that gelsolin level, which decreases during apoptosis resulting from conditions such as trauma, begins to increase in the cerebrospinal fluid in the acute phase after administering sildenafil in the early post-traumatic period. This indicates that tissue damage and apoptosis are reduced by sildenafil, which has been histologically proven in this study. Spinal hematoma and necrosis in white and gray matter were lesser in the rabbit group treated with sildenafil after trauma than in the control group; this finding supports the neuroprotective activity of sildenafil (17). In our study showing similar results, sildenafil citrate may have increased cerebral blood flow and decreased neuronal cell death at the cellular level during the acute phase through all these mechanisms, namely the NOcGMP pathway.

Intracranial pressure is the most important issue in TBI. The fact that sildenafil citrate causes vasodilatation suggests that it may increase intracranial pressure. According to Dhar et al. and Washington et al. sildenafil did not change intracranial pressure in their patient with SAH $(10,39)$. They found that despite acute reduction in mean arteriel pressure, global cerebral blood flow did not change, and vasoconstriction due to SAH was prevented. Although these studies differ in terms of the methodology; the mechanism is similar with respect to TBI.

According to some studies, there is hypoperfusion due to decreased blood flow in the acute period of trauma $(23,28)$. Furthermore, parenchymal bleeding caused by microvessel shearing leads to reflex vasoconstriction in and around the damaged area in early TBI (19). Endothelin-1, a potent cerebral vasoconstrictor, has an important role in early brain injury (25). Studies have reported that sildenafil also reduces endothelin levels (29). Based on these mechanisms, we think that sildenafil citrate decreases neuronal death by increasing blood supply in the acute phase.

Edema following head trauma increases the intracranial pressure and results in decreased cerebral perfusion pressure and cerebral blood flow, thus causing ischemia $(9,16,18)$. Thus, controlling the increased intracranial pressure in trauma patients is the most important step of the treatment. Osmotic therapy is applied in this phase. Although mannitol (20\%) is currently considered the gold standard hyperosmolar agent, hypertonic saline solutions are also considered very effective in decreasing the intracranial pressure $(5,32)$. In the current study, we compared sildenafil citrate with mannitol, which is still frequently used in treating head trauma.

To the best of our knowledge, no studies have yet reported the effects of sildenafil on head trauma. In the current study, rats with induced head trauma were administered mannitol or sildenafil in the acute phase to investigate the possible protective effects of these agents against injuries caused by trauma.

Significant inferences can be made based on the results of our study. First, the significant results obtained from the comparison between Group I and II indicate that the trauma model selected by us was successfully applied. Second, the results obtained from the comparison between Group II and III and between Group II and IV indicate that mannitol reduces neuronal death following head trauma and has neuroprotective activity. In the comparison between sildenafil and mannitol, no difference was observed between the two groups in terms of neuronal death.

The Stereo Investigator Software (Micro Bright Field) used for histological evaluation generates unbiased virtual counting spaces and ensures a more reliable counting process (13). In addition, we believe that the statistically significant results obtained for the histological evaluation in both the prefrontal and hippocampal regions in all rats improve the reliability of our results.

\section{LIMITATIONS}

The lack of investigation of biochemical parameters supporting cell death/life in blood or damaged tissues is a limitation of this study. However, histological evaluation enables direct monitoring of neuronal death. Therefore, the false positive/ negative results that we encounter during the analysis of biochemical parameters are considerably decreased because of histological evaluation. Another limitation of the present study is that a short period of time (4 hours) has been assessed after TBI. Future researchers should consider evaluating the neuroprotective activity of sildenafil citrate treatment by using different doses and durations. 


\section{CONCLUSION}

In conclusion, we believe that sildenafil citrate can be a useful adjunct or alternative agent for the clinical treatment of patients with acute TBI.

\section{ACKNOWLEDGMENTS}

Preparation for publication of this article is partly supported by Turkish Neurosurgical Society.

\section{REFERENCES}

1. Abd-Elfattah Foda MA, Marmarou A: A new model of diffuse brain injury in rats. Part II: Morphological characterization. J Neurosurg 80(2):301-313, 1994

2. Atalay B, Caner H, Cekinmez M, Ozen O, Celasun B, Altinors $\mathrm{N}$ : Systemic administration of phosphodiesterase $\mathrm{V}$ inhibitor, sildenafil citrate, for attenuation of cerebral vasospasm after experimental subarachnoid hemorrhage. Neurosurgery 9(5):1102-1108, 2006

3. Benjamins JA, Nedelkoska L: Cyclic GMP-dependent pathways protect differentiated oligodendrocytes from multiple types of injury. Neurochem Res 32(2):321-329, 2007

4. Bivalacqua TJ, Champion HC, Hellstrom WJ, Kadowitz PJ: Pharmacotherapy for erectile dysfunction. Trends Pharmacol Sci 21(12):484-489, 2000

5. Boone MD, Oren-Grinberg A, Robinson TM, Chen CC, Kasper EM: Mannitol or hypertonic saline in the setting of traumatic brain injury: What have we learned? Surg Neurol Int 6:177, 2015. Available from: http://surgicalneurologyint. com/surgicalint-articles/mannitol-or-hypertonic-saline-in-thesetting-of-traumatic-brain-injury-what-have-we-learned/

6. Charriaut-Marlangue C, Nguyen T, Bonnin P, Duy AP, Leger PL, Csaba Z, Pansiot J, Bourgeois T, Renolleau S, Baud O: Sildenafil mediates blood-flow redistribution and neuroprotection after neonatal hypoxia-ischemia. Stroke 45(3):850-856, 2014

7. Chen XM, Wang NN, Zhang TY, Wang F, Wu CF, Yang JY: Neuroprotection by sildenafil: Neuronal networks potentiation in acute experimental stroke. CNS Neuroscience \& Therapeutics 20(1):40-49, 2014

8. Davis AE: Mechanisms of traumatic brain injury: Biomechanical, structural and cellular considerations. Crit Care Nurs Q 23(3): $1-13,2000$

9. DeWitt D, Jenkins L, Prough D: Enhanced vulnerability to secondary ischemic insults after experimental traumatic brain injury. New Horiz 3(3):376-383, 1995

10. Dhar R, Washington C, Diringer M, Zazulia A, Jafri H, Derdeyn C, Zipfel G: Acute effect of intravenous sildenafil on cerebral blood flow in patients with vasospasm after subarachnoid hemorrhage. Neurocrit Care 25(2):201-204, 2016

11. Fiscus RR: Involvement of cyclic GMP and protein kinase $G$ in the regulation of apoptosis and survival in neural cells. Neurosignals 11(4):175-190, 2002

12. Ghajar J: Traumatic brain injury. Lancet 356(9233):923-929, 2000
13. Golub VM, Brewer J, Wu X, Kuruba R, Short J, Manchi M, Swonke M, Younus I, Samba Reddy D: Neurostereology protocol for unbiased quantification of neuronal injury and neurodegeneration. Front Aging Neurosci 7:196, 2015

14. Han BH, Vellimana AK, Zhou M-L, Milner E, Zipfel GJ: Phosphodiesterase 5 inhibition attenuates cerebral vasospasm and improves functional recovery after experimental subarachnoid hemorrhage. Neurosurgery 70(1):178-187, 2011

15. Hartwell RC, Sutton LN: Mannitol, intracranial pressure, and vasogenic edema. Neurosurgery 32(3):444-450, 1993

16. Ikeda Y, Long DM: The molecular basis of brain injury and brain edema: The role of oxygen free radicals. Neurosurgery 27(1):1-11, 1990

17. Kara H, Degirmenci S, Ak A, Bayir A, Kayis SA, Uyar M, Akinci M, Acar D, Kocacan M, Akyurek F: Neuroprotective effects of sildenafil in experimental spinal cord injury in rabbits. Bosnian Journal of Basic Medical Sciences 15(1):38, 2015

18. Katayama Y, Tsubokawa T, Miyazaki S, Kawamata T, Yoshino A: Oedema fluid formation within contused brain tissue as a cause of medically uncontrollable elevation of intracranial pressure: The role of surgical therapy. Brain Edema VIII. Acta Neurochir 51:308-310, 1990

19. Kramer DR, Winer JL, Pease BA, Amar AP, Mack WJ: Cerebral vasospasm in traumatic brain injury. Neurol Res Int 2013:1-7, 2013

20. Luvisotto TL, Auer RN, Sutherland GR: The effect of mannitol on experimental cerebral ischemia, revisited. Neurosurgery 38(1):131-139, 1996

21. Maas Al, Stocchetti N, Bullock R: Moderate and severe traumatic brain injury in adults. Lancet Neurol 7(8):728-741, 2008

22. Marmarou A, Foda MAA-E, Brink Wvd, Campbell J, Kita $\mathrm{H}$, Demetriadou K: A new model of diffuse brain injury in rats: Part I: Pathophysiology and biomechanics. J Neurosurg 80(2):291-300, 1994

23. Martin NA, Patwardhan RV, Alexander MJ, Africk CZ, Lee $\mathrm{JH}$, Shalmon E, Hovda DA, Becker DP: Characterization of cerebral hemodynamic phases following severe head trauma: Hypoperfusion, hyperemia, and vasospasm. J Neurosurg 87:9-19, 1997

24. Ozdegirmenci O, Kucukozkan T, Akdag E, Topal T, Haberal A, Kayir H, Oter S, Akyol M, Uzbay T: Effects of sildenafil and tadalafil on ischemia/reperfusion injury in fetal rat brain. The Journal of Maternal-Fetal\&Neonatal Medicine 24(2):317-323, 2011

25. Perrein A, Petry L, Reis A, Baumann A, Mertes PM, Audibert G: Cerebral vasospasm after traumatic brain injury: An update. Minerva Anestesiol 81(11):1219-1228, 2015

26. Pluta RM: Delayed cerebral vasospasm and nitric oxide: Review, new hypothesis, and proposed treatment. Pharmaco Ther 105(1):23-56, 2005

27. Prado J, Pifarre P, Giralt M, Hidalgo J, Garcia A: Metallothioneins $\mathrm{I} / \mathrm{II}$ are involved in the neuroprotective effect of sildenafil in focal brain injury. Neurochem Int 62(1):70-78, 2013

28. Prat R, Markiv V, Dujovny M, Misra M: Evaluation of cerebral autoregulation following diffuse brain injury in rats. Neurol Res 19:393-402, 1997 
29. Proietti M, Aversa A, Letizia C, Rossi C, Menghi G, Bruzziches R, Merla A, Spera G, Salsano F: Erectile dysfunction in systemic sclerosis: Effects of longterm inhibition of phosphodiesterase type-5 on erectile function and plasma endothelin-1 levels. J Rheumatol 34:1712-1717, 2007

30. Puzzo D, Staniszewski A, Deng SX, Privitera L, Leznik E, Liu S, Zhang H, Feng Y, Palmeri A, Landry DW, Arancio O: Phosphodiesterase 5 inhibition improves synaptic function, memory, and amyloid- $\beta$ load in an Alzheimer's disease mouse model. J Neurosci 29(25):8075-8086, 2009

31. Royl G, Balkaya M, Lehmann S, Lehnardt S, Stohlmann K, Lindauer U, Endres M, Dirnagl U, Meisel A: Effects of the PDE5-inhibitor vardenafil in a mouse stroke model. Brain Res 1265:148-157, 2009

32. Scalfani MT, Dhar R, Zazulia AR, Videen TO, Diringer MN: Effect of osmotic agents on regional cerebral blood flow in traumatic brain injury. J Crit Care 27(5):526.e7-12, 2012

33. Struck MB, Andrutis KA, Ramirez HE, Battles AH: Effect of a short-term fast on ketamine-xylazine anesthesia in rats. $\mathrm{J} \mathrm{Am}$ Assoc Lab Anim Sci 50(3):344-348, 2011

34. Thurman D, Guerrero J: Trends in hospitalization associated with traumatic brain injury. Jama 282(10):954-957, 1999

35. Uthayathas S, Karuppagounder SS, Tamer SI, Parameshwaran K, Degim T, Suppiramaniam V, Dhanasekaran M: Evaluation of neuroprotective and anti-fatigue effects of sildenafil. Life Sci 81(12):988-992, 2007

36. Wakita H, Tomimoto H, Akiguchi I, Lin JX, Ihara M, Ohtani $\mathrm{R}$, Shibata M: Ibudilast, a phosphodiesterase inhibitor, protects against white matter damage under chronic cerebral hypoperfusion in the rat. Brain Res 992(1):53-59, 2003

37. Walder B, Haller G, Rebetez MM, Delhumeau C, Bottequin E, Schoettker P, Ravussin P, Brodmann Maeder M, Stover JF, Zürcher M, Haller A, Wäckelin A, Haberthür C, Fandino J, Haller $\mathrm{CS}$, Osterwalder J: Severe traumatic brain injury in a highincome country: An epidemiological study. J Neurotrauma 30(23):1934-1942, 2013
38. Wang L, Zhang ZG, Zhang RL, Chopp M: Activation of the PI3-K/Akt pathway mediates cGMP enhanced-neurogenesis in the adult progenitor cells derived from the subventricular zone. J Cereb Blood Flow Metab 25(9):1150-1158, 2005

39. Washington CW, Derdeyn CP, Dhar R, Arias EJ, Chicoine MR, Cross DT, Dacey RG Jr, Han BH, Moran CJ, Rich KM, Vellimana AK, Zipfel GJ: Phase I proof-of-concept and safety trial of sildenafil to treat cerebral vasospasm following subarachnoid hemorrhage. J Neurosurg 124(2):318-327, 2016

40. Weimann J, Ullrich R, Hromi J, Fujino Y, Clark MW, Bloch KD, Zapol WM: Sildenafil is a pulmonary vasodilator in awake lambs with acute pulmonary hypertension. Anesthesiology 92(6):1702-1712, 2000

41. Yazdani A, Khoja Z, Johnstone A, Dale L, Rampakakis E, Wintermark $P$ : Sildenafil improves brain injury recovery following term neonatal hypoxia-ischemia in male rat pups. Dev Neurosci 38(4):251-263, 2016

42. Yilmaz N, Dulger H, Kiymaz N, Yilmaz C, Gudu BO, Demir I: Activity of mannitol and hypertonic saline therapy on the oxidant and antioxidant system during the acute term after traumatic brain injury in the rats. Brain Res 1164:132-135, 2007

43. Zhang L, Zhang RL, Wang Y, Zhang C, Zhang ZG, Meng H, Chopp M: Functional recovery in aged and young rats after embolic stroke: Treatment with a phosphodiesterase type 5 inhibitor. Stroke 36(4):847-852, 2005

44. Zhang L, Zhang Z, Zhang RL, Cui Y, LaPointe MC, Silver B, Chopp M: Tadalafil, a long-acting type 5 phosphodiesterase isoenzyme inhibitor, improves neurological functional recovery in a rat model of embolic stroke. Brain Res 1118(1):192-198, 2006 